\title{
Sustainable development of smart textiles: a review of 'self-functioning' abilities which makes textiles alive
}

\author{
Abstract \\ Smart textiles, which are the textiles with innovative and technological applications, \\ can receive and give responses to the external stimuli so as to accommodate themselves \\ to changes in surrounding. 'Self-functioning' is an ability of a matter for performing \\ a specific process or response on its own automatically towards a corresponding \\ requirement. In recent decades, the implementation of smart textiles with various \\ 'self-functioning' capabilities has been opened up increasingly. It would be a vital \\ role for maintaining the sustainability of textile and clothing industry. In this paper, a \\ general review of smart textiles with the three 'self-functioning' abilities is addressed \\ and divided into the following sections: \\ a. Smart fabrics with 'self-cleaning' ability; \\ b. Smart textiles with 'self-healing' ability and \\ c. Smart textile apparels with 'self-thermoregulation' ability.
}

\author{
Volume 4 Issue 2 - 2018 \\ Tin Wai Cheung, Li Li \\ Institute of Textiles and Clothing, the Hong Kong Polytechnic \\ University, Hong Kong \\ Correspondence: Li Li,Associate Professor, Fashion \& Textile \\ Design, Institute of Textiles and Clothing, the Hong Kong \\ Polytechnic University, Hong Kong, Tel 2766 4I 06, Email \\ li.lilly@polyu.edu.hk
}

Received: January 23, 2018 | Published: March 16, 2018

Keywords: Body image; Social anxiety; Psychological distress

\section{Introduction}

Technologically-friendly and user-friendly textile products, which can make daily life more convenient and comfortable, are progressively popular in modern society. Going along with the advanced development of innovative technology, textile clothing is no longer only used as body shielding for protection, warmth keeping at cold weather and aesthetic enhancing for fashion design. Furthermore, it can provide different 'self-functioning' processes for interacting with and adapting to external changes like living organisms. Various applications can hence be initiated for propelling the textile industry forward.

Smart textiles with 'self-functioning' capabilities are widely acknowledged of bringing great benefits to the sustainable development of society and to promote the quality of life as well. The three popular 'self-functioning' textiles, which include self-cleaning, self-healing and self-thermoregulation, are introduced in this review. Self-cleaning textiles can degrade dirt particles and organic substances by themselves in order to remove stains, bacteria or odour. ${ }^{1-13}$ Fabrics with self-healing function can repair the torn surface automatically for extending the textiles' life span. ${ }^{14-22}$ Functional fabrics with selfthermoregulation ability can respond to temperature changes and provide thermal comfort. ${ }^{23-29}$

In this review paper, smart textiles with the three 'self-functioning' abilities are generally introduced,

i. Smart fabrics with 'self-cleaning' ability;

ii. Smart textiles with 'self-healing' ability and

iii. Smart textile apparels with 'self-thermoregulation' ability (Figure 1).

\section{Lotus Effect}

\section{Easy to Clean Finishing}

Gecko-adhesive Tape

Photocatalytic Coating

Self-functioning Textiles

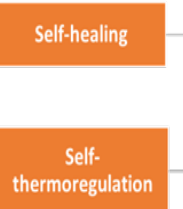

Coating and Finishing

Phase Change Material

Thermal Electronic Garment

Figure I Summary of the Three Self-functioning Textiles: i) Self-cleaning, ii) self-healing and iii) self-thermoregulation 


\section{Smart fabrics with 'self-cleaning' ability by photocatalysis}

A fabric with self-cleaning function is known to be capable in cleaning the textile itself (i.e. decomposing or removing dirts) automatically that can reduce human effort, detergents and water required in cleaning. The functions for self-cleaning include dirt and organic substances decomposition, pollutant degradation, deodorization, anti-mould, and anti-bacteria.

\section{Development of 'self-cleaning' textile systems}

Self-cleaning textiles were initially studied with the nanotechnology inspired by the concept of 'Lotus Effect'. It was observed that the nano-hair-like structures of the micro-bumpy cells of lotus leaves could promote the hydrophobicity, water repellency and the removal of dirt particles. ${ }^{2,3}$ Therefore, the self-cleaning textiles, which had micro-rough surfaces for easy clearance of dirt particles and effective water repellent, had been successfully investigated based on the biomimetic simulation of the 'Lotus Effect'.

More textile-based self-cleaning systems have also been developed for various cleaning purposes. Easy to Clean (ETC) nanotechnology finishing can be used to coat the textile surfaces for enhancing the removal of dirt particles, reducing the adhesion of proteins and promoting the antibacterial properties of the surfaces; 4,5 Geckoadhesive tape is an adhesive self-cleaning system. The micro-fibers of the tape can capture the particulates through the adhesive nature and the shear movement; ${ }^{6}$ the anti-fouling function can be taken effect by the steric repulsion between proteins and the hydrated polymer chains of the self-assembled monolayers (SAMs) coating. ${ }^{7}$ In recent years, photocatalytic coating is a popular approach for developing self-cleaning textiles. Photocatalysts, which are able to absorb light energy and decompose the organic matters during the process of photo catalysis, had been utilized for the invention of new self-cleaning textiles. Titanium dioxide $\left(\mathrm{TiO}_{2}\right)$, zinc oxide $(\mathrm{ZnO})$ and porphyrins are the significant examples of photocatalysts.

\section{Mechanism of photocatalytic self-cleaning textiles}

The photosensitizer (PS) of photocatalysts induces the selfcleaning ability. Through the absorption of light energy (i.e. photons), one of the electrons of PS molecule is excited from the singlet state to an excited state. Then, the excited triplet state of PS is produced when there is light energy lost during the intersystem crossing of the excited singlet state. Afterwards, PS returns back to its original ground state for regeneration. Two types of photooxidative pathways can be performed by the excited triplet state of PS. Reactive oxygen substances and hydroxyl radicals can be produced during the process. ${ }^{8}$ Self-cleaning can be achieved through the oxidative decomposition of dirts and contaminants.

\section{Examples of self-cleaning textiles by using photocatalysts}

The study of titanium dioxide $\left(\mathrm{TiO}_{2}\right)$ coatings on textile surfaces had been reported in current years. Nano-crystalline $\mathrm{TiO}_{2}$ finishing on cotton fabrics' surface by dip-pad-dry-cure process had been produced. 'Self-cleaning' degradation of the organic materials such as colorant, red wine, coffee stains and bacteria under ultra-violet (UV) irradiation was successfully shown., ${ }^{910}$ Self-cleaning wool fabrics had also been developed with $\mathrm{TiO}_{2} / \mathrm{SiO}_{2}$ coating. Effective removal of coffee stains under UV irradiation was reported. ${ }^{11}$ Although the significant performance of degrading organic matters by photocatalysts under UV light had been verified; it is also favorable in exploring the photocatalytic decomposition under visible light as it occupies the majority of sunlight at around $44 \%$ of a whole. Based on the UV-Vis Absorption Spectra, it was known that a photocatalyst called porphyrin consisted of a strong absorption peak (soret band) at the region from 400 to $450 \mathrm{~nm}$ and the other absorption ( $\mathrm{Q}$ band) from 500 to $700 \mathrm{~nm} .{ }^{12}$ Furthermore, another investigation on the UVVis Absorption Spectra of porphyrins was done. It was observed that both the copper (II) porphyrin $\left(\mathrm{CuTCPP} / \mathrm{TiO}_{2}\right)$ coated cotton fabric and the $\mathrm{TCPP} / \mathrm{TiO}_{2}$ coated specimen could absorb visible light at the region from 400 to $700 \mathrm{~nm}$ while there was no typical absorption could be identified for the $\mathrm{TiO}_{2}$ coated fabric. ${ }^{13}$ Therefore, porphyrins was thought to be more capable in absorbing visible light energy (i.e from 400 to $700 \mathrm{~nm}$ ) when comparing with $\mathrm{TiO}_{2}$. By examining the result of the Methylene Blue (MB) photocatalytic degradation, more significant performance was shown by the cotton fabric coated with $\mathrm{TCPP} / \mathrm{TiO}_{2}$ than that coated with $\mathrm{TiO}_{2}$ alone (Figure 2). ${ }^{12}$

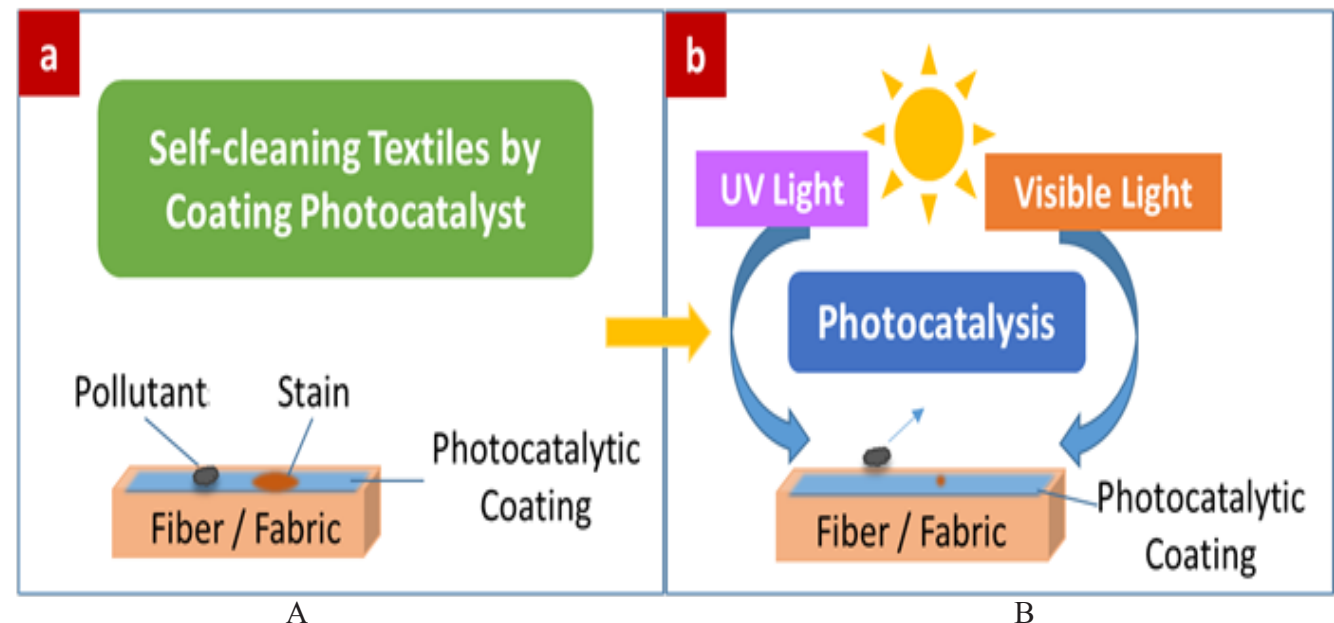

Figure 2 Self-cleaning Textiles by Coating Photocatalyst: (a) Photocatalytic coating is initially applied on the fabric surface. (b) Successful removal of contaminants and stains by photocatalysis

Effective applications of self-cleaning textiles

Numerous studies had provided evidences about the effectiveness of removing stains and colorants by using self-cleaning technology on textiles. Other significant applications such as decontamination of toxic chemicals and anti-bacteria had also been investigated. 
Polyelectrolyte multilayers (PEM) films with an enzyme called organophosphorous hydrolase (OPH) were initially applied on textile threads. Fabrics were then knitted with the use of these coated threads. Hydrolysis and decontamination of methyl parathion pesticide had been done by these self-cleaning fabrics. The fabrics are believed to be an essential for making smart protective garments with the self-decontaminating ability. ${ }^{30}$ For anti-bacterial application, the enhancement of the bactericidal performance by the $\mathrm{TiO}_{2}$ coating on cotton had been examined. It was found that the bactericidal performance could be promoted with the increasing contact surface area of coating. Besides, it could also be a protective layer from eliminating the risk of bacterial adhesion within the biofilms. ${ }^{10}$

\section{Smart fabrics with 'self-healing' ability}

Self-healing fabrics, which are known as one of the smart textiles with automatic self-repairing function, are thought to be a promising essential for the continuous expansion of textile industry.

\section{Self-healing textiles by coating}

The self-healing textiles have been conventionally developed with the use of chemical coating finishes in forms of microcapsules, hydrogels or other polymeric matrices. Encapsulation of dicyclopentadiene (DCPD) would be one of the common types of the coating finishes. When the microcapsules are damaged by an elongated fissure, the encapsulated self-repairing components (DCPD) would release along the open fissure. Self-repairing mechanism can hence be preceded by the polymerization between the monomers and catalysts ${ }^{14-16}$ (Figure 3 ). In addition to the utilization of chemical coating, it was reported that the finishes were not only applicable in self-healing of damaged fissures but also in restoring the hydrophobicity of the fabric surface. The study of the PDMS and Octadecylamine (ODA) coated polyester fabric is an example. The self-healing process of superhydrophobicity could be resulted by the decomposition of the PDMS/ODA coating and the further migration of the underlying hydrophobic polymer chains towards the fabric surface. ${ }^{17}$
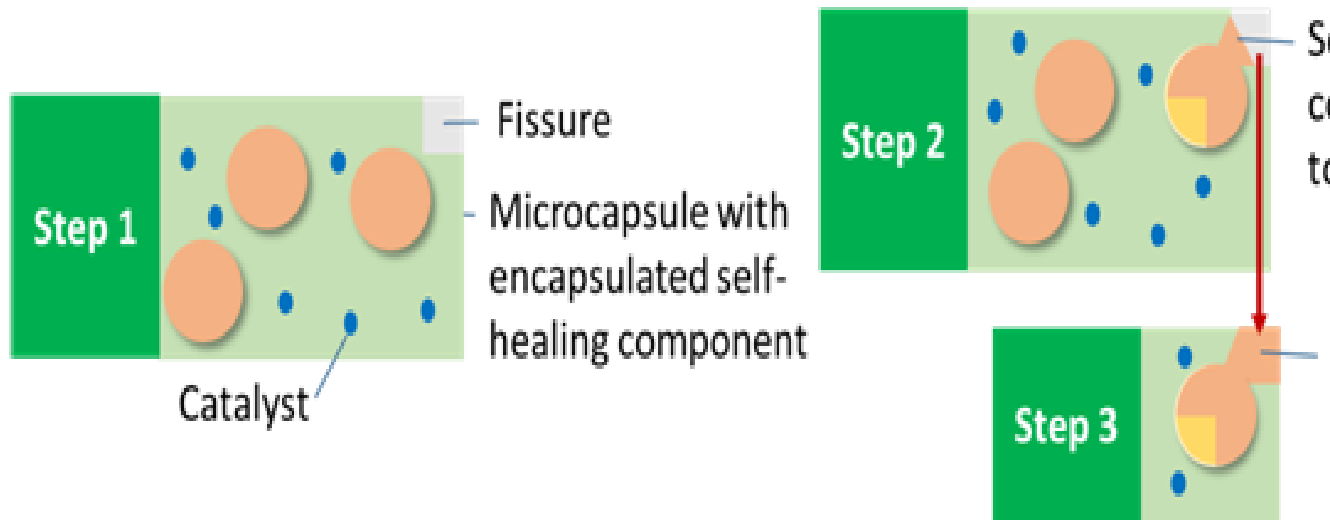

Self-healing component is released towards the fissure

\section{Polymerization of} fissure occurs

Figure 3 Self-healing Textiles by Microencapsulation of Healing Agent: When the microcapsules are damaged by an open fissure, the encapsulated selfrepairing components would release towards it. Self-repairing mechanism occurs by polymerization of fissures ${ }^{14^{-}} 16$

The self-healing fabrics with healing coating technology, which was inspired by the self-healing proteins in squid ring teeth, would be one of the exceptional discoveries through the bottom-up process of biomimicry. Gaddes et al. ${ }^{18}$ reported that the squid ring teeth (SRT) proteins comprised with semi-crystalline construction, flexible and rigid structure and high elastic modulus that contributing towards the properties of self-repairing. During the investigation, a polyelectrolyte film with SRT proteins had been applied onto a torn area of a textile surface as a self-repairing coating. Once a tear is made in the area with the SRT-coating, self-repairing occurred with the given condition of warm water and pressure. It was because the SRT protein could alter and become softer in warm water which was higher than the glass transition temperature. A strong adhesive bond could be formed and retained by the amphorous region of SRT protein (Figure 4). Due to the future implementation of self-healing apparel system, the research team had tried to encapsulate enzymes (urease) with the SRT-containing films. It was discovered that the enzymatic activity could be performed after the self-healing process. Since enzyme could neutralize and break down toxic chemicals, this self-healing fabrics are suggested for making industrial apparels which can break down the toxic chemicals accumulated in surroundings. ${ }^{18,19}$ It is believed that medical garments for breaking down the hazardous and infectious materials could also be produced with the enzyme contained selfhealing fabrics.

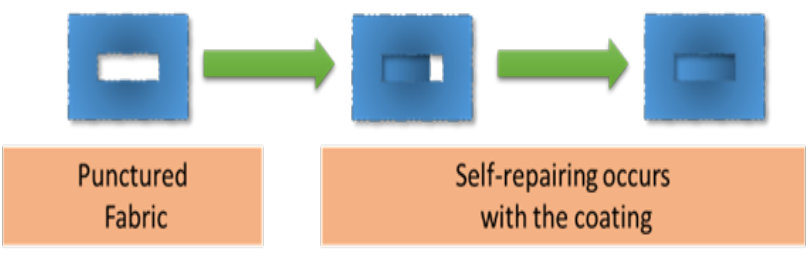

Figure 4 Self-healing Coating Technology

Future expectations of using self-healing textiles in fashion and clothing

Integrating 'self-healing' function into fashion and clothing would be a prospective and sustainable feature of fashion industry. As hosiery and stockings are easily punctured by sharp objects or by long-term wear, coating self-healing membrane or finishes on the inner side of stockings would be a promising and prompt solution to reduce the chance of embarrassment occurs. Besides, applying selfhealing coating or finishes would also increase the quality of knitwear by reducing the damage of unravelling. Apart from the application in fashion products, the self-healing fabrics are also expected to be used in making medical textiles in order to prolong their therapeutic and protective function.

Based on the biomimetic inspiration of natural resources, scientists 
had also discovered that the self-healing fabricated membrane could be also simulated by the parenchyma cells of a plant called vine Aristolochia. A biomimetic close-cellular polyurethane foamy layer, which could be coated on the inner part of a membrane for minimizing the problem of air leakage through the punctured holes, had been created by simulating the self-repairing mechanism of the plant (i.e. fissures of the plant can be self-healed by the internal-pressurized parenchyma cells). Therefore, internal pressure was initially applied into the foamy layer of membrane so as to imitate the pre-stresses of the cells. If a hole is punctured by a sharp material, the pre-pressurized foamy layer can seal and expand into the hole. Therefore, the problem of air leakage can be eliminated. Due to the significant result of selfhealing, the membranes have been utilized as an important material for making pneumatic roof and constructing bridges. ${ }^{20-22}$

This concept would be a vital step for future implementation of textile based foamy layers. These foamy layers are believed to offer great impacts on making garments with pneumatic system. Continuous protection, rehabilitation or healthcare could be consequently enhanced. For examples, the therapeutic function of the healthcare mattresses such as for pressure ulcers or bed sores can be maintained for a longer duration if they are made of the self-healing textile foams. Besides, it is also thought that the foams can also be used in making the paddings of shoes. Thus, the cushioning function can be extended by the self-repairing effect once the padding is damaged.

\section{Smart textile apparels with 'self- thermoregulation' ability}

Thermal regulation is a response of living organisms to maintain their internal body temperature and homeostasis in spite of the changes of environmental temperature. However, the normal ability of performing thermal regulation may become poorer when ageing or it may be affected by neurological diseases. Besides, the thermal regulation stability of human body would also be influenced when living in extreme weather conditions, facing temperature fluctuation and doing extreme physical exercises. Thereupon, smart textile apparels with 'self-thermoregulation' function have been extensively manufactured for promoting the heat balance, stability and comfort of human body. Two types of self-thermo regulated textiles, which are the phase change materials and electronic textiles, are reported.

Phase change materials (PCM) have been one of the significant elements for making smart clothing that can process automatic thermal regulation. These materials can help to absorb and store the latent heat energy in a liquid phase at a high temperature; while the stored heat energy is released when the temperature drops and the PCM changes into solid phase (Figure 5). Integrating PCMs into textiles can be done by a variety of methods such as by encapsulating the PCMs into the microcapsules; adding the micro-capsulated PCMs into polymeric solution during traditional spinning so as to form PCM-contained fibers or yarns; incorporating the PCM-contained microcapsules with fabrics by using binder; laminating the PCMcontained film into the internal layer of fabrics. Hydrated inorganic salt, paraffin wax, polyethylene glycol (PEG), hydrocarbons, and fatty acids are the examples of PCMs. It is acknowledged that the 'selfthermo regulaton' function of the smart clothing can be exhibited by the automatic thermal regulating effect provided by the encapsulated PCMs. The thermal regulating effect is realized by absorbing or releasing heat energy in response to an increase or decrease in the environmental temperature respectively. As a result, the absorbed heat can assist in cooling down while the released heat can help to warm the human body. The surrounding temperature can also be maintained at a stable and constant level. ${ }^{23-27}$

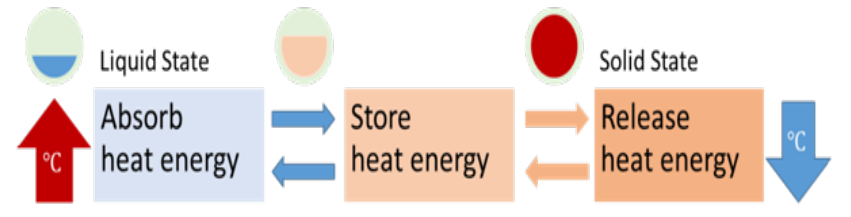

Figure 5 Mechanisms of Phase Change Materials (PCMs). Heat energy is absorbed by PCMs (liquid state) at a high temperature; while the stored heat energy is released when the temperature decreases. PCMs changes from liquid into solid state

Electronic textiles (e-textiles), which are defined as fabrics that consist of electronic, digital or computational devices, have a wide range of potential applications in human monitoring and body temperature regulation through the interconnection of a large-scale sensor networks. The spectrum of e-textile ranges from wearable electronic attachment on textile substrates to wearable electronic textiles made with conductive materials. Thermal functionality is a crucial topic in wearable electronic textiles that is significant to health, safety and resistance to extreme environments. These intelligent textiles with self- thermoregulation function will be employed in various applications such as for medical uses, military fields, extreme sports and athletes. For instance, thermal electronic garments can enhance the thermal comfort and regulation by using conductive fabrics. It was reported that the conductive fabrics can be made by combining both conductive yarns and normal yarns together during the knitting process. Electrical power was applied onto the thermal garment. The rate of heat distribution through the conductive yarns could be regulated towards the change of temperature until equilibrium was reached between the heat loss and the electrical power supply. A constant and stable temperature can hence be kept with the garment. ${ }^{28,29}$

\section{Implementation of self-thermo regulated textile applications}

Self-thermoregulation have been abundantly developed for different applications in textiles and clothing, which include the applications in sportswear, protective garments, bedclothes, intimate apparels, medical textiles and furnishing fabrics. ${ }^{30}$ Phase-change materials (PCMs) in making cooling vest for firefighters are one of the examples of protective garments. Through the experiment, it was found that the body temperature and skin temperature could be diminished when wearing the vest. ${ }^{31}$ For making medical-thermo electronic textiles, conductive fabric was an important constituent to connect the electronic components for health monitoring and therapy. WEALTHY, which is a wearable health monitoring system, was made by knitting electrodes and integrating electronic sensing devices into conductive fabric. Instant and individual monitoring of patients' status could be performed effectively, comfortably and conveniently. ${ }^{32}$ Conductive fabrics with high stretchability had been made by polymerization. It aimed to investigate whether the fabric conductivity for electrotherapy could be maintained with extension. Based on the experimental results, the conductivity could be preserved with $40 \%$ extension for more than 30 cycles. ${ }^{33}$ 


\section{Conclusion and outlook}

Technological advancement of smart textiles with 'self-functioning' abilities would be a promising life-long project. The 'self-functioned' smart textile is believed to be more and more important for daily life convenience and a good quality of life. This paper reviews the three 'self-functioning' smart textiles (i.e. self-cleaning, self-healing and self-thermoregulation) by introducing the materials, mechanism and related examples.

It is expected that the 'self-functioning' smart textiles can be further developed with versatile and applicable design. For examples, unexpected blood stains may appear on the back side of trousers or skirts when menstruation comes suddenly. However, the blood stains may not be realized and removed instantly. Thus, a self-cleaning fabric, which can degrade the blood stains thoroughly and automatically, would be a favorable solution for avoiding this situation. For the fabric with 'self-healing' function, it is believed to be a good substrate for making garments or apparels which are easily damaged by a sharp object or due to serious abrasion. The 'self-thermoregulation' clothing would be a potential therapeutic product for eliminating the risk of having hypothermia while exposing to cold weather condition during a long period.

\section{Acknowledgements}

This work was supported by central Research Grant (PolyU $156028 / 15 \mathrm{H})$

\section{Conflicting interest}

Authors declare there is no conflict of interest in publishing the article

\section{References}

1. Gupta D, Gulrajani ML. Self cleaning finishes for textiles. In: Paul R, editor. Functional finishes for textiles: improving comfort, performance and protection. Cambridge: Woodhead Publishing, Elsevier, 2014. 257

2. Mattila H. Yarn to Fabric: Intelligent Textiles. In: Sinclair R, editor Textiles and fashion: materials, design and technology. Cambridge: Woodhead Publishing, Elsevier, 2014. 368 p

3. Black S. The role of nanotechnology in sustainable textiles. In Blackburn R, editor. Sustainable textiles: life cycle and environmental impact. Cambridge: Woodhead Publishing, 2009. 394 p.

4. Bahners T, Mittal K. Striving for self-cleaning textiles - critical thoughts on current literature. In: Mittal K L, Bahners T, editors. Textile Finishing. Recent Developments and Future Trends. Hoboken, NJ: John Wiley \& Sons and Beverly, MA: Scrivener Publishing, 2017. 137 p.

5. Aromaa M, Pimenoff JA, Makela JM. Liquid flame spray as a means to achieve nanoscale coatings with easy-to-clean properties. In: Daoud WA, editor. Self-cleaning materials and surfaces: a nanotechnology approach. West Sussex: John Wiley \& Sons, 2013.

6. Röhrig M. Fabrication and analysis of bio-inspired smart surfaces Karlsruhe: KIT Scientific Publishing, 2014:51-70.

7. Li B, Ye Q. Antifouling surfaces of self-assembled thin layer. In: Zhou F, editor. Antifouling surfaces and materials from land to marine environment, Berlin: Springer, 2015:31-54.

8. Zhuo J. Photoactive chemicals for antimicrobial textiles. In: Sun G, editor. Antibacterial textiles, Cambridge: Woodhead Publishing, Elsevier, 2016:197-223.
9. Qi K, Wang X, Xin JH. Photocatalytic self-cleaning textiles based on nanocrystalline titanium dioxide. Textile ResearchJ.2011;81(1):101-110.

10. Qi K, Daoud WA, Xin JH, et al. Self-cleaning cotton. J Materials Chemistry. 2006;16(47):4567-4574.

11. Pakdel E, Daoud WA, Wang X. Self-cleaning and superhydrophilic wool by $\mathrm{TiO} / 2 / \mathrm{SiO}$, nanocomposite. Applied surface science. 2013;275:397-402.

12. Afzal S, Daoud WA, Langford S J. Self-cleaning cotton by porphyrinsensitized visible-light photocatalysis. Journal of Materials Chemistry. 2012;22(9):4083-4088.

13. Afzal S, Daoud WA, Langford SJ. Photostable Self-cleaning cotton by a copper (II) porphyrin/TiO visible-light photocatalytic system. ACS Applied Materials \& Interfaces. 2013;5(11):4753-4759.

14. Jassal M, Agrawal AK. Speciality polymers for the finishing of technical textiles. In: Gulrajani ML, editor. Advances in the dyeing and finishing of technical textiles. Cambridge: Woodhead Publishing, Elsevier, 2013: 309-354.

15. Meirowitz R. Microencapsulation technology for coating and lamination of textiles. In: Smith WC, editor. Smart textile coatings and laminates. Cambridge: Woodhead Publishing, Elsevier, 2010. 320 p.

16. Brown EN, Kessler MR, Sottos NR, et al. In situ poly (urea-formaldehyde) microencapsulation of dicyclopentadiene. $J$ microencapsulation. 2003;20(6):719-730.

17. Xue $\mathrm{CH}$, Bai X, Jia ST. Robust, self-healing superhydrophobic fabrics prepared by one-step coating of PDMS and octadecylamine. Scientific Reports. 2016;6:27262.

18. Gaddes D, Jung H, Pena-Francesch A, et al. Self-healing textile: enzyme encapsulated layer-by-layer structural proteins. ACS applied materials \& interfaces. 2016;8(31):20371-20378.

19. Sariola V, Pena-Francesch A, Jung H, et al. Segmented molecular design of self-healing proteinaceous materials. Scientific reports. 2015;5: 13482

20. Rampf M, Speck O, Speck T, et al. Self-repairing membranes for inflatable structures inspired by a rapid wound sealing process of climbing plants. J Bionic Engineering. 2011;8(3):242-250.

21. Masselter T, Speck T. Quantitative and qualitative changes in primary and secondary stem organization of aristolochia macrophylla during Ontogeny: functional growth analysis and experiments. $J$ experimental botany. 2008;59(11):2955-2967.

22. Busch S, Seidel R, Speck O, et al. Morphological aspects of self-repair of lesions caused by internal growth stresses in stems of Aristolochia macrophylla and Aristolochia ringens. Proceedings of the Royal Society of London B: Biological Sciences. 2010;277(1691):2113-2120.

23. Mondal S. Phase change materials for smart textiles - An overview. Applied Thermal Engineering. 2008;28(11):1536-1550.

24. Salaün F, Devaux E, Bourbigot S, et al. Thermoregulating response of cotton fabric containing microencapsulated phase change materials. Thermochimica Acta. 2010;506(1):82-93.

25. Pause B. Phase Change Materials and their application in coatings and laminates for textiles. In: Smith WC, editor. Smart textile coatings and laminates. Cambridge: Woodhead Publishing, Elsevier, 2010:236-246.

26. Yuan Y, Zhang N, Tao W, et al. Fatty acids as phase change materials: review. Renewable \& Sustainable Energy Reviews. 2014;29:482-498.

27. Hu J, Murugesh Babu K. The use of smart materials in cold weather apparel. In: WIlliams JT, editor. Textiles for cold weather apparel. Cambridge: Woodhead Publishing, Elsevier, 2009. 432 p. 
28. Tong J, Li L. Thermal regulation of electrically conducting fabrics In: Tao X, editor. Handbook of Smart Textiles, Singapore: Springer, 2015:689-718.

29. Tong JH, Liu S, Yang C X, et al. Modeling of package-free flexible conductive fabric with thermal regulation where temperature can be customized. Textile Research J. 2015;85(6):590-600.

30. Singh A, Lee Y, Dressick WJ. Self-cleaning fabrics for decontamination of organophosphorous pesticides and related chemical agents. Advanced materials. 2004;16(23-24):2112-2115.
31. Gao C. Phase-change materials (PCMs) for warming or cooling in protective clothing. 2nd ed. Wang F, Gao C, editors. Protective clothing: managing thermal stress. Cambridge: Woodhead Publishing, Elsevier, 2014. 500 p.

32. Paradiso R, Loriga G, Taccini N. A wearable health care system based on knitted integrated sensors. IEEE transactions on Information Technology in biomedicine. 2005;9(3):337-344.

33. Oh KW, Park HJ, Kim SH. Stretchable conductive fabric for electrotherapy. J Applied Polymer Science. 2003;88(5):1225-1229. 